\begin{tabular}{|c|c|}
\hline Title & Redox reactions of small organic molecules using ball milling and piezoelectric materials \\
\hline Author(s) & Kubota, Koji; Pang, Y adong; Miura, A kira; Ito, Hajime \\
\hline Citation & $\begin{array}{l}\text { Science, 366(6472), 1500-1504 } \\
\text { https://doi.org/10.1126/science.aay } 8224\end{array}$ \\
\hline Issue Date & $2019-12-20$ \\
\hline DOC URL & http:/hdl.handle.net/2115/76621 \\
\hline Rights & 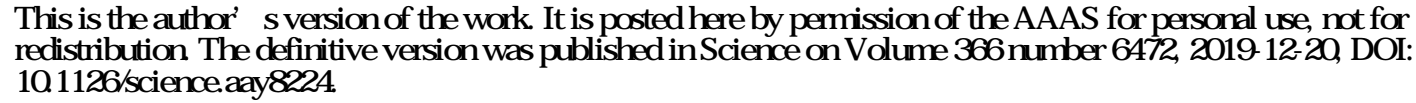 \\
\hline Type & article (author version) \\
\hline File Information & revised manuscript.pdf \\
\hline
\end{tabular}

Instructions for use 


\title{
Redox Reactions of Small Organic Molecules Using Ball Milling and Piezoelectric Materials
}

\author{
Koji Kubota $^{1,2 *}$, Yadong Pang ${ }^{2}$, Akira Miura ${ }^{2}$, Hajime Ito $^{1,2 *}$
}

\author{
Affiliations: \\ ${ }^{1}$ Institute for Chemical Reaction Design and Discovery (WPI-ICReDD), Hokkaido University, \\ Sapporo, Hokkaido 060-8628, Japan. \\ ${ }^{2}$ Division of Applied Chemistry, Graduate School of Engineering, Hokkaido University, \\ Sapporo, Hokkaido 060-8628, Japan. \\ *Correspondence to: hajito@eng.hokudai.ac.jp (H.I.), kbt@eng.hokudai.ac.jp (K.K.)
}

\begin{abstract}
Over the past decade, photoredox catalysis has harnessed light energy to accelerate bond-forming reactions. We postulated that a complementary method for the redox-activation of small organic molecules in response to applied mechanical energy could be developed through the piezoelectric effect. Here, we report that agitation of piezoelectric materials via ball milling reduces aryl diazonium salts. This mechanoredox system can be applied to arylation and borylation reactions under mechanochemical conditions.
\end{abstract}

One Sentence Summary: The first examples of arylation and borylation reactions using mechanically induced piezoelectricity have been developed.

Main Text: Visible-light photoredox catalysis represents a key recent development in contemporary organic synthesis $(1-5)$. In these transformations, the photoexcited catalyst can act as a potent single-electron oxidant, transferring an electron to an acceptor (A), after which singleelectron oxidation of a donor (D) affords the product under concomitant regeneration of the ground state catalyst (Fig. 1A). The broad success of photoredox catalysis hinges on the susceptibility of the coupling partners to redox activation and ensuing bond-forming reactions with high levels of efficiency and selectivity.

There has likewise been substantial parallel progress in mechanochemical organic transformations using ball milling $(6-18)$. Since the term mechanochemistry was introduced by Ostwald in 1887, mechanochemical synthesis has been extensively exploited in materials science $(6-8)$, polymer chemistry (9), and inorganic synthesis (8), but its application to organic synthesis is more recent $(10-18)$. Advantages of the approach include the avoidance of potentially harmful organic solvents and external heating, shorter reaction times, and simpler operational handling. In addition, mechanochemical reactions are particularly useful for substrates that are poorly soluble in common organic solvents.

Inspired by the unique profile of photoredox systems based on light irradiation and the utility of ball milling in mechanochemistry, we hypothesized that redox activation of small organic molecules could be achieved through a mechanistically distinct approach using mechanical energy 
(19-22). In particular, we envisioned that the agitation of piezoelectric materials (23-35) via ball milling could generate temporarily highly polarized particles that might act as strong reductants to transfer electrons to small organic molecules, followed by oxidative quenching of a donor, thus inducing the selective formation of bonds in a manner analogous to photoredox catalysis (Fig. 1B). Such a mechanoredox approach could potentially represent a powerful and attractive strategy to reduce the environmental impact of chemical processes; photoredox approaches, similar to other conventional organic reactions, often require complicated reaction set-ups, substantial amounts of dry and degassed organic solvents as well as an inert gas atmosphere $(1-5)$.

For a proof-of-concept study, we selected commercially available, inexpensive, and easyto-handle $\mathrm{BaTiO}_{3}$ nanoparticles as the piezoelectric material (Fig. 1B). This choice was motivated by pioneering studies, in which ultrasonic agitation of $\mathrm{BaTiO}_{3}$ produces a suitable electrochemical potential to overcome the water splitting potential $(1.23 \mathrm{~V})(28,29)$ and reduce a $N, N, N^{\prime}, N^{\prime}, N^{\prime \prime}, N^{\prime \prime}-$ hexamethyl[tris(aminoethyl)amine] ( $\left.\mathrm{Me}_{6} \mathrm{TREN}\right)$-ligated $\mathrm{CuBr}_{2}$ complex, which has a reduction potential of $-0.30 \mathrm{~V}$ (vs. SCE) $(29,36)$. These studies suggested that mechanical agitation of $\mathrm{BaTiO}_{3}$ in a ball mill could generate an electrochemical potential suitable for the activation of redox-active small organic molecules in organic synthesis.

The photoredox systems that activate aryl diazonium salts for coupling with heteroarenes (37) or borylation (38) have been reported by König and Yan, respectively. The key step in these transformations is the photochemical reduction of aryl diazonium salts to aryl radical species. Andrieux and Pinson have reported a reduction potential of $-0.16 \mathrm{~V}$ (vs. SCE) for phenyl diazonium tetrafluoroborate (39), which was within range for feasible redox activation using $\mathrm{BaTiO}_{3}$. In our postulated mechanism (Fig. 1C), the agitation of $\mathrm{BaTiO}_{3}$ via ball milling generates a temporary electrochemical potential in response to mechanical impact. According to the aforementioned inorganic studies $(28,29)$, the temporary polarization should be sufficiently persistent to reduce an aryl diazonium salt (1) via a SET mechanism analogous to the photoredox reaction, to furnish the corresponding aryl radical $\mathbf{I}$. The addition of $\mathbf{I}$ to heteroarene $\mathbf{2}$ would afford radical addition intermediate II, which would be subsequently oxidized by the hole in the agitated $\mathrm{BaTiO}_{3}$ to form carbocation intermediate III (37). Finally, deprotonation of III would lead to arylation product 3 . In the borylation (38), the generated radical $\mathbf{I}$ reacts with bis(pinacolate)diboron (4), to cleave the B-B bond, resulting in the formation of the boryl substitution product $\mathbf{5}$ as well as radical anion intermediate IV. Subsequently, oxidation of $\mathbf{I V}$ by the agitated $\mathrm{BaTiO}_{3}$ could form $\mathrm{F}-\mathrm{B}($ pin $)(\mathbf{V})$ as a byproduct. 
A

Photoredox system (well-established)

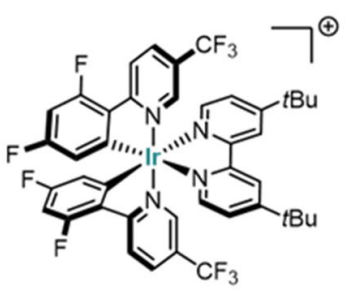

$\operatorname{Ir}\left[\mathrm{dF}\left(\mathrm{CF}_{3}\right) \mathrm{ppy}\right]_{2}(\mathrm{dtbpy})^{+}$

B

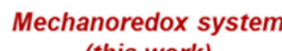
(this work)

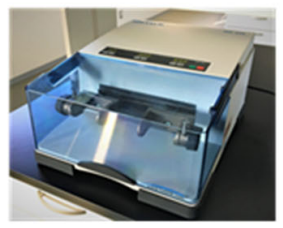

Ball mill and piezoelectric materials
General photoredox paradigm (oxidative quenching)
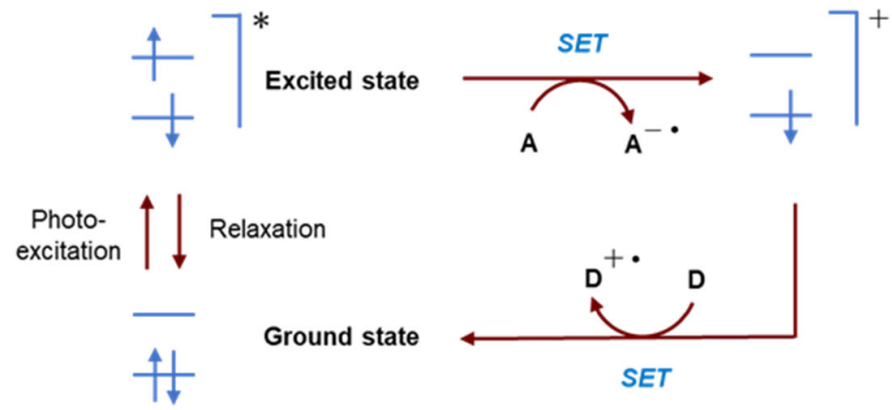

Proposed mechanoredox paradigm (oxidative quenching)

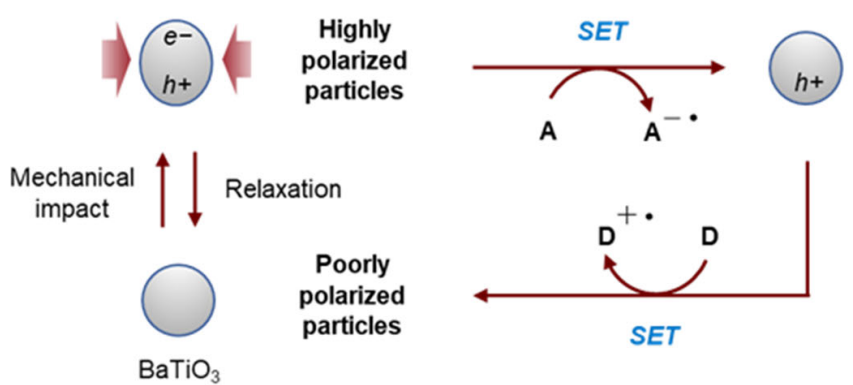

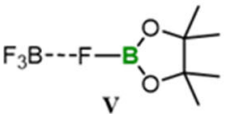
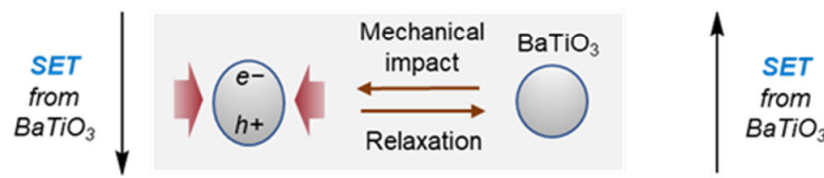<smiles>[R]c1ccc(C2[X]C=CC2C=C)cc1</smiles>

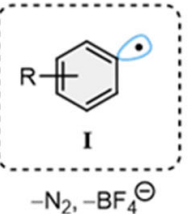

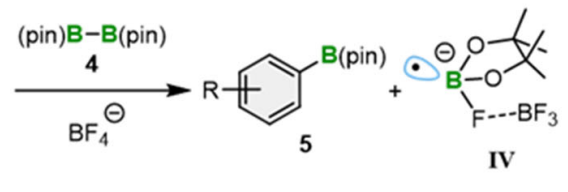

Mechanoredox arylation pathway

Fig. 1. Working hypothesis for a mechanoredox system for the activation of small organic molecules in organic synthesis. (A) A commonly employed photoredox catalyst and a generic photoredox oxidative quenching cycle. (B) Proposed mechanoredox paradigm using a ball mill and a piezoelectric material. (C) Proposed mechanism for the mechanoredox arylation and borylation using $\mathrm{BaTiO}_{3}$ and ball milling. SET: single-electron transfer.

To explore this mechanistic hypothesis, we first attempted the proposed mechanoredox $\mathrm{C}-\mathrm{H}$ arylation with $\mathbf{1 a}$ and furan (2a) in the presence of commercially available $\mathrm{BaTiO}_{3}$ using a 
Retch MM400 mixer mill (1.5 mL stainless-steel milling jar with 5-mm diameter stainless-steel ball) (Fig. 2A). The corresponding arylation product (3a) was obtained in $40 \%$ yield after milling at $20 \mathrm{~Hz}$ for $1 \mathrm{~h}$ under air. The reaction did not proceed in the absence of $\mathrm{BaTiO}_{3}$, suggesting that the mechanical energy provided by ball milling generated the piezoelectric potential to reduce $\mathbf{1 a}$. In contrast, even when ultrasound irradiation was applied to the mixture with $\mathrm{BaTiO}_{3}$ in dimethyl sulfoxide (DMSO) under a nitrogen atmosphere, the formation of the product was not observed. A small amount of 3a was obtained when the reaction was carried out in the presence of $\mathrm{SrTiO}_{3}$, which exhibits piezoelectric properties upon applying in-plain strain (40). When using nonpiezoelectric ceramic materials, such as $\mathrm{TiO}_{2}, \mathrm{BaCO}_{3}$, or $\mathrm{Al}_{2} \mathrm{O}_{3}$, the reaction did not proceed, which suggests that piezoelectric materials are essential for this arylation reaction. We found that conducting the reaction at higher ball-milling frequency $(30 \mathrm{~Hz})$ significantly improved the yield $(81 \%)$. This result is consistent with our hypothesis that the required piezoelectric potential is generated by mechanical force provided by the ball milling of $\mathrm{BaTiO}_{3}$. Using other piezoelectric materials, such as $\mathrm{LiNbO}_{3}$ and $\mathrm{ZnO}$, also afforded 3a, albeit in lower yield $(24 \%$ and $15 \%$, respectively). Using a bigger jar $(5.0 \mathrm{~mL})$ and ball $(7.5 \mathrm{~mm})$ provided 3a in high yield $(82 \%$, Table S2). Product 3a was isolated by filtration of the obtained crude solid mixture (Fig. 2B), followed by column chromatography on silica gel.

A

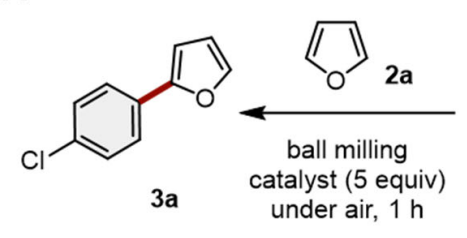

Optimization for mechanoredox arylation

\begin{tabular}{ccc} 
catalyst & $\begin{array}{c}\text { milling } \\
\text { frequency }(\mathrm{Hz})\end{array}$ & $\begin{array}{c}\text { NMR yield } \\
\text { of } 3 \mathbf{a}(\%)\end{array}$ \\
\hline $\mathrm{BaTiO}_{3}$ & 20 & 40 \\
none & 20 & $<1$ \\
$\mathrm{BaTiO}_{3}$ & - & $<1^{*}$ \\
$\mathrm{SrTiO}_{3}$ & 20 & 3 \\
$\mathrm{TiO}_{2}$ & 20 & $<1$ \\
$\mathrm{BaCO}_{3}$ & 20 & $<1$ \\
$\mathrm{Al}_{2} \mathrm{O}_{3}$ & 20 & $<1$ \\
$\mathrm{BaTiO}_{3}$ & 30 & 81 \\
$\mathrm{LiNbO}_{3}$ & 30 & 24 \\
$\mathrm{ZnO}$ & 30 & 15 \\
\hline
\end{tabular}

*In DMSO with ultrasound under $\mathrm{N}_{2}$.

\section{B}

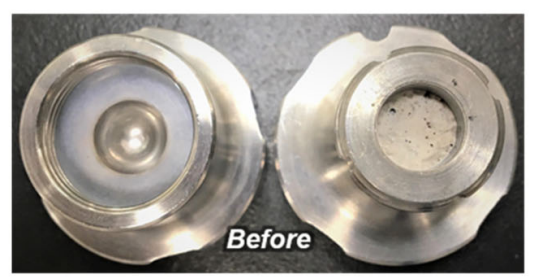

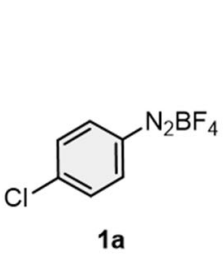

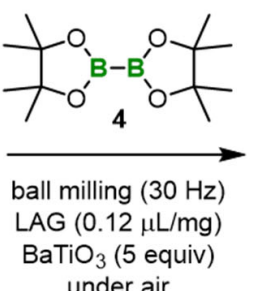<smiles>Clc1ccc(Br)cc1</smiles>

$5 a$

under air

Optimization for mechanoredox borylation

\begin{tabular}{ccc} 
LAG & time $(\mathrm{h})$ & $\begin{array}{c}\text { NMR yield } \\
\text { of } \mathbf{5 a}(\%)\end{array}$ \\
\hline none & 1 & 21 \\
MeCN & 1 & 54 \\
DMF & 1 & 37 \\
DMSO & 1 & 13 \\
toluene & 1 & 11 \\
hexane & 1 & 15 \\
MeCN & 1.5 & 62 \\
MeCN & 3 & 89 \\
MeCN & 3 & $<1^{*}$ \\
\hline${ }^{*}$ Reaction was carried out without BaTiO
\end{tabular}

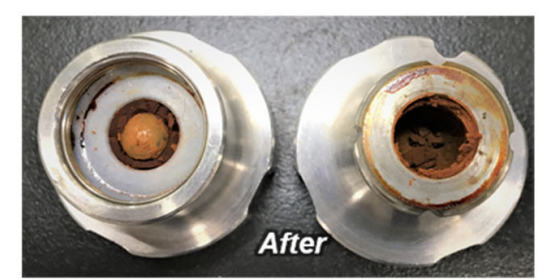

Fig. 2. Mechanoredox arylation and borylation using mechanical force. (A) Optimization of the mechanoredox arylation and borylation reactions. (B) Reaction mixture of the mechanoredox 
arylation of $2 \mathrm{a}$ after grinding in a ball mill. A stainless-steel milling jar $(1.5 \mathrm{~mL})$ and a stainlesssteel ball (diameter: $5 \mathrm{~mm}$ ) were used. See supplementary materials for details.

We then investigated the possibility of mechano-redox borylation using the same setup (Fig. $2 \mathrm{~A})$. We found that the borylation of $\mathbf{1 a}$ with 4 in the presence of $\mathrm{BaTiO}_{3}$ afforded the desired arylboronate (5a) in $21 \%$ yield. Next, we attempted to improve the reactivity by using liquidassisted-grinding (LAG), in which a substoichiometric amount of liquid is added (41). In all LAG reactions, the ratio of liquid additive $(\mu \mathrm{L})$ to reactant $(\mathrm{mg})$ was 0.12 . Use of acetonitrile $(\mathrm{MeCN})$ as the LAG additive improved the yield of 5a, while other common solvents, such as $N, N$ dimethylformamide (DMF), DMSO, toluene, or hexane led to little or no improvement. We also found that prolonging the reaction time led to a higher yield of $\mathbf{3 a}(89 \%)$ when $\mathrm{MeCN}$ was used as the LAG additive. Using a bigger jar $(5.0 \mathrm{~mL})$ and ball $(7.5 \mathrm{~mm})$ did not significantly affect the transformation $\left(86 \%\right.$, Table $\mathrm{S} 3$ ). The reaction without $\mathrm{BaTiO}_{3}$ did not proceed, supporting our mechanistic hypothesis. Compared with the analogous photoredox reaction, the present mechanoredox borylation exhibited much faster reaction kinetics and a better product yield (38).

Subsequently, we explored the scope of the mechanoredox arylation reaction with various aryl diazonium salts using a $5 \mathrm{~mL}$ stainless-steel milling jar with a $7.5-\mathrm{mm}$ diameter stainless-steel ball (Fig. 3A). Electron-deficient aryl diazonium salts (1a-1h) were converted into the desired products (3a-3h) in good yield under the optimized conditions. Simple aromatic substrates (1i-1k) also reacted to give the corresponding products (3i-3k) in good yield. However, in the case of an electron-rich methoxy-substituted diazonium salt (1I), the product (3I) was obtained in relatively low yield. This was probably due to the relatively high reduction potential of $\mathbf{1 1}$. Other heteroarenes, namely, thiophene and pyrrole, successfully reacted to form the desired products (3m and $\mathbf{3 n}$ ). Arylation reactions using thienyl diazonium salts afforded the corresponding heterobiaryls ( $\mathbf{3 o}$ and 3p), which are typical structural motifs for organic semiconductors (42). Minor regioisomers (3 mb and $3 \mathbf{p b}$ ) were observed as competing products in the reactions with thiophene, whereas the photoredox system developed by König and co-workers, using Eosin Y, produced 3ma and 3pa as single isomers (37). We also confirmed that the developed mechanoredox borylation conditions were applicable to a variety of aryl diazonium salts (Fig. 3B).

To demonstrate the practical utility of this protocol, we investigated a gram-scale synthesis of heterobiaryls under the developed mechanoredox conditions, as well as the recycling of $\mathrm{BaTiO}_{3}$ (Fig. 4A and 4B). The mechanoredox C-H arylation of furan (2a) with 10 was carried out on a 8mmol scale in a 25 -mL stainless-steel ball-milling jar with one 15 -mm diameter stainless steel ball, affording 30 in $71 \%$ yield (Fig. 4A). After separation from the crude reaction mixture and washing, $\mathrm{BaTiO}_{3}$ could be reused for the mechanoredox arylation of furan (2a) under the same reaction conditions at least three times before the yield of 3k declined substantially (Fig. 4B). 
A Scope of mechanoredox arylation

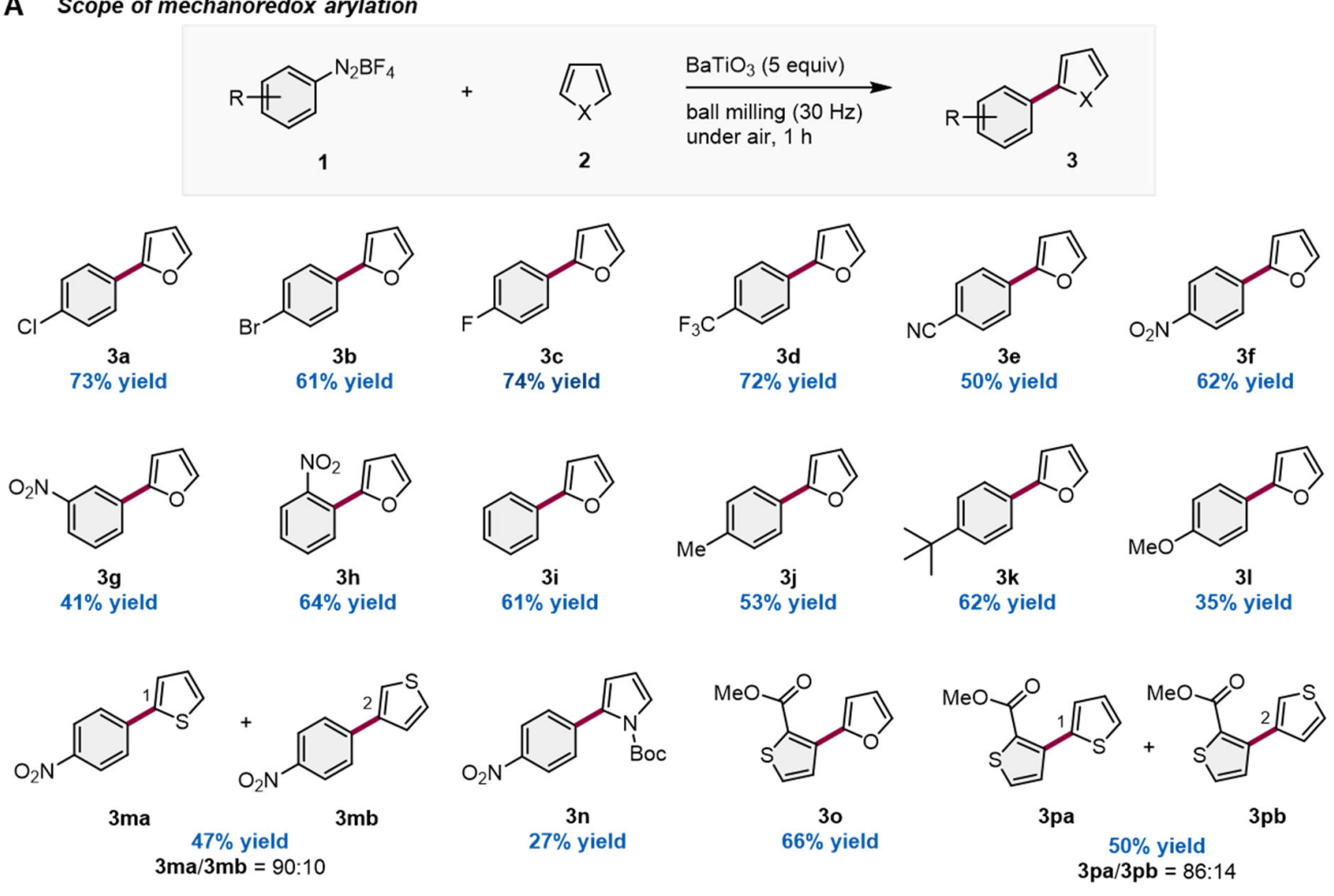

B Scope of mechanoredox borylation

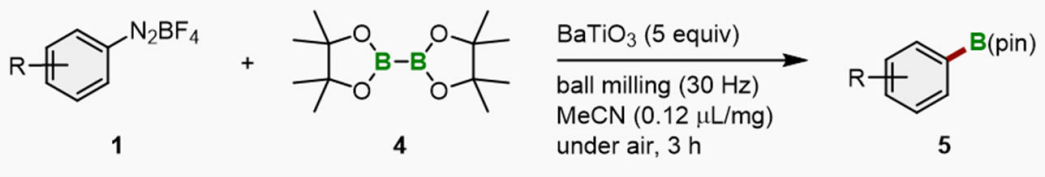<smiles>Clc1ccc(Br)cc1</smiles>

$5 a$

$61 \%$ yield

(86\% NMR)<smiles>N#Cc1ccc(Br)cc1</smiles>

$5 f$

$45 \%$ yield

(58\% NMR)

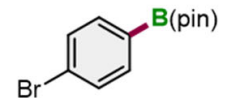

$5 b$

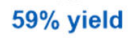

(75\% NMR)<smiles>O=[N+]([O-])c1cccc(Br)c1</smiles>

$5 \mathrm{~g}$

$36 \%$ yield

(52\% NMR)

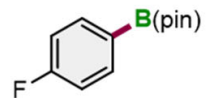

$5 \mathrm{c}$

$70 \%$ yield

(85\% NMR)

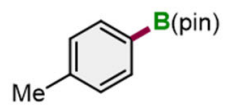

$5 \mathrm{~h}$

$70 \%$ yield

(77\% NMR)

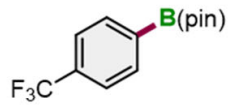

$5 d$

$45 \%$ yield

(73\% NMR)

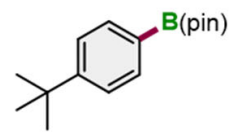

$5 i$

$61 \%$ yield

(70\% NMR)<smiles>O=[N+]([O-])c1ccc(Br)cc1</smiles>

$5 e$ (69\% NMR)<smiles>COc1ccc(Br)cc1</smiles>

$5 \mathrm{j}$

$80 \%$ yield (84\% NMR)

Fig. 3. Scope of the mechano-redox arylation and borylation reactions using aryl diazonium salts. Data for each entry (in bold) are reported as isolated yield percentages. ${ }^{1} \mathrm{H}$ NMR integrated yields are shown in parentheses. (A) Substrate scope of the mechanoredox arylation of heteroaromatic compounds. (B) Substrate scope of the mechanoredox borylation of aryl diazonium salts. Reactions were performed at $0.3 \mathrm{mmol}$ scale using a stainless-steel milling jar $(5 \mathrm{~mL})$ and stainless-steel ball (diameter: $7.5 \mathrm{~mm})$. Arylation conditions: 1 (0.3 mmol), 2 (4.5 mmol), $\mathrm{BaTiO}_{3}$ 
(1.5 mmol). Borylation conditions: 1 (0.3 mmol), 4 (0.3 mmol), $\mathrm{BaTiO}_{3}(1.5 \mathrm{mmol}), \mathrm{MeCN}(0.12$ $\mu \mathrm{L} / \mathrm{mg})$. See supplementary materials for details.

\section{A Gram-scale synthesis}

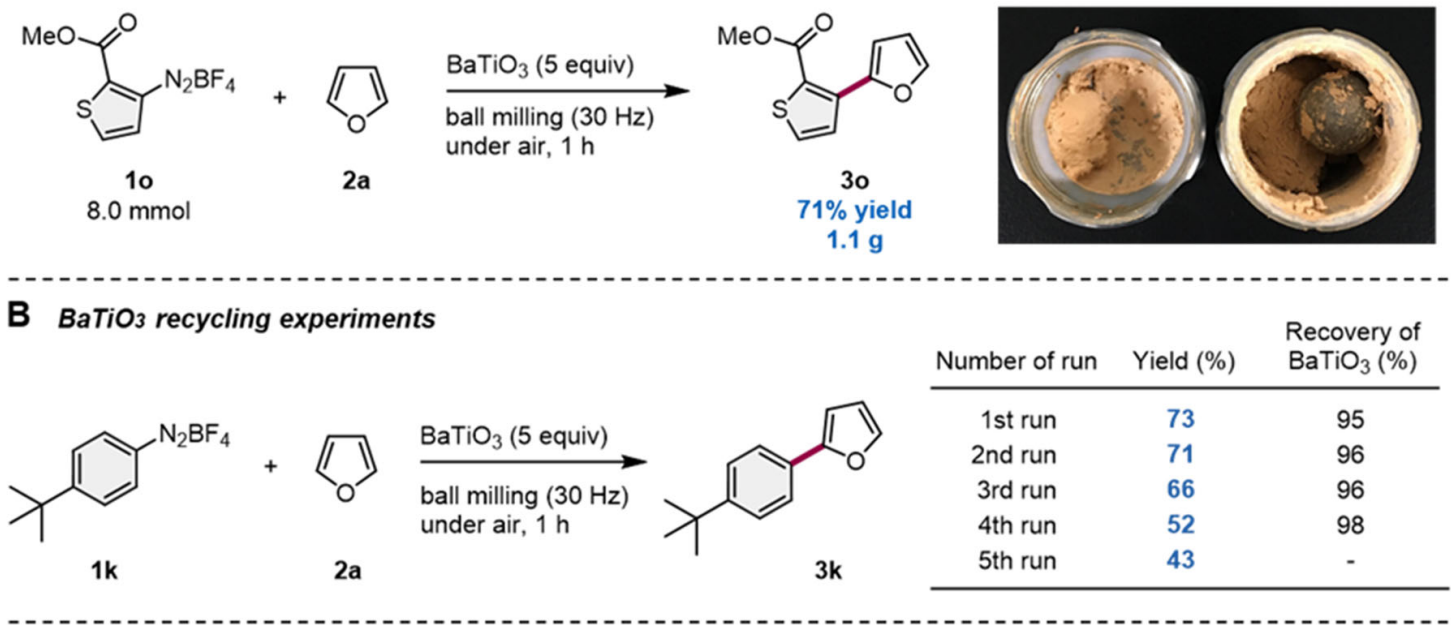

C Direct PAHs functionalization<smiles>O=[N+]([O-])c1ccc(N(Br)c2ccccc2)cc1</smiles>

1f

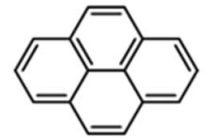

$6 a$

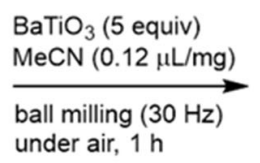
under air, $1 \mathrm{~h}$<smiles>O=[N+]([O-])c1ccc(-c2ccc3ccc4c5c(ccc2c35)=CCC4)cc1</smiles>

7 aa<smiles>CC=CC</smiles>

$7 \mathrm{ab}$

$78 \%$ yield

$7 a a / 7 a b=92: 8$<smiles>O=[N+]([O-])c1ccc(N=[18O])cc1</smiles>

1f

$+$<smiles>c1cc2ccc3ccc4ccc5ccc6ccc1c1c2c3c4c5c61</smiles>

$6 b$

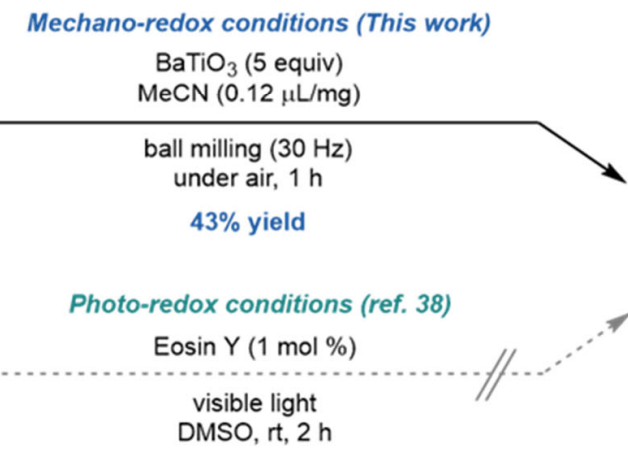

no reaction<smiles></smiles>

$7 \mathrm{~b}$

Fig. 4. Exploration of a gram-scale synthesis, catalyst recycling, and the arylation of polyaromatic hydrocarbon compounds. (A) Mechanoredox arylation of $\mathbf{2 a}$ with 10 on the gram scale using a 25-mL ball-milling jar (picture on the right). (B) $\mathrm{BaTiO}_{3}$ recycling experiments using 1k and 2a. (C) Mechanoredox arylation of the polyaromatic hydrocarbons 6 with 1f. See supplementary materials for details. 
Direct $\mathrm{C}-\mathrm{H}$ arylation of polycyclic aromatic hydrocarbons (PAHs) has attracted considerable interest $(43,44)$ on account of their role in organic light-emitting diodes, organic photovoltaics, organic semiconductors, and organic thin-film transistors. With this in mind, we conducted a preliminary investigation of the feasibility of the $\mathrm{C}-\mathrm{H}$ arylation of PAHs using our mechanoredox approach (Fig. 4C). The reaction of $\mathbf{1 f}$ with pyrene (6a) in the presence of $\mathrm{BaTiO}_{3}$ and a small amount of MeCN as the LAG additive afforded the desired $\mathrm{C}-\mathrm{H}$ arylation product (7aa) in good yield with high regioselectivity $(\mathbf{7 a a} / 7 \mathbf{a b}=92: 8)$. Furthermore, coronene $(\mathbf{6 b})$ was also arylated in moderate yield under the mechanoredox conditions. When the arylation of coronene (6b) was attempted via König's photoredox procedure using Eosin Y, no reaction occurred (37). This was probably due to the low solubility of coronene (6b) in the polar solvents required for such photoredox reactions. These results demonstrate the promising potential of the mechanoredox arylation as an operationally simple and mild route to synthesize functionalized PAHs from poorly soluble substrates that are incompatible with photoredox conditions.

We postulated that the mechanoredox $\mathrm{C}-\mathrm{H}$ arylation and borylation were proceeding via SET events, in which an aryl radical is generated through piezoelectric reduction (Fig. 1C); this assumption is supported by the results of preliminary mechanistic investigations (Fig. 5). When 2,2,6,6-tetramethylpiperidinoxyl (TEMPO) (8) was treated with aryl diazonium salt 1a in the absence of furan (2a), the TEMPO-trapped intermediate 9 was obtained (Fig. 5A). Furthermore, the addition of TEMPO (8) to a reaction mixture containing 1a, furan (2a), and $\mathrm{BaTiO}_{3}$ halted the arylation process, and the TEMPO-trapped intermediates $\mathbf{9}$ and $\mathbf{1 0}$ were detected (Fig. 5A). Compound 10 might have been formed through the reaction of TEMPO (8) with the intermediate II (Fig. 1C), followed by oxidative aromatization by $\mathrm{BaTiO}_{3}$ or atmospheric oxygen. Overall, the identified compounds suggest that the mechano-redox activation with $\mathrm{BaTiO}_{3}$ proceeds via a radical pathway.

We used a scanning electron microscopy (SEM) analysis to confirm that the mechanical stimulus provided by ball milling is transferred onto the $\mathrm{BaTiO}_{3}$ particles under the applied conditions (Fig. 5B) (24). The SEM image of commercially available $\mathrm{BaTiO}_{3}$ powder shows a regular shape of the $\mathrm{BaTiO}_{3}$ particles before the reaction (approximate size: $<75 \mu \mathrm{m}$ ) [Fig. 5B (i)]. Subsequently, the powder was subjected for $60 \mathrm{~min}$ to ball milling at $30 \mathrm{~Hz}$ and then analyzed by SEM. The resulting image clearly shows a dramatic distortion of the shape and a decrease in the size of the $\mathrm{BaTiO}_{3}$ particles [Fig. 5B (ii)]. These results suggest that the mechanical stimulus provided by ball milling is efficiently transferred onto the $\mathrm{BaTiO}_{3}$ particles, which would result in the generation of localized electrochemical potentials on the surface of the $\mathrm{BaTiO}_{3}$ particles that can be used for the activation of the aryl diazonium salts.

To investigate whether the friction during ball milling generates a thermal effect, the temperature inside the milling jar during the mechanoredox arylation of $\mathbf{2 a}$ with $\mathbf{1 a}$ was measured using thermography immediately after opening the jar (Fig. 5C). The crude mixtures were prepared under optimized conditions. The obtained image showed that the temperature after arylation in the ball mill was around $30{ }^{\circ} \mathrm{C}$, thus discounting the possibility of thermal activation of the aryldiazonium salts to generate aryl radical species by the heat provided from ball milling. 
A

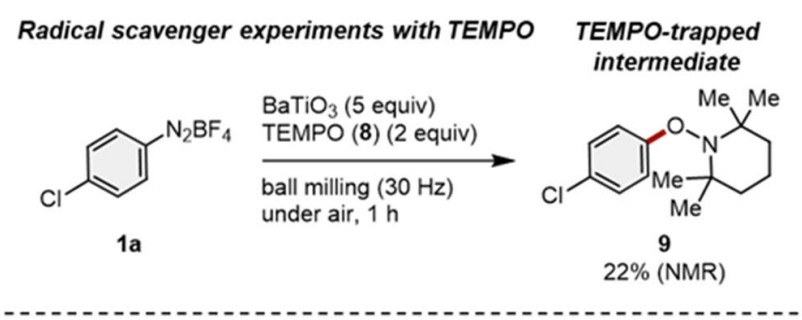

Radical scavenger experiment with $1 \mathrm{a}$ and $2 a$

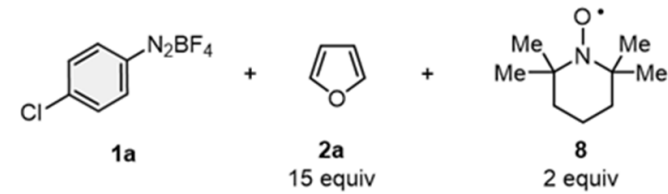

$\mathrm{BaTiO}_{3}$ (5 equiv) $\downarrow \begin{aligned} & \text { ball milling }(30 \mathrm{~Hz}) \\ & \text { under air, } 1 \mathrm{~h}\end{aligned}$

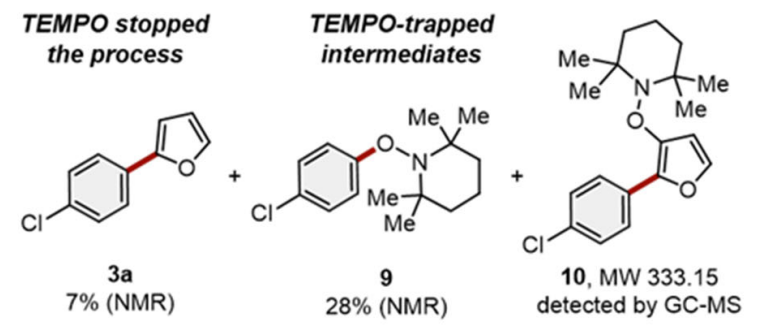

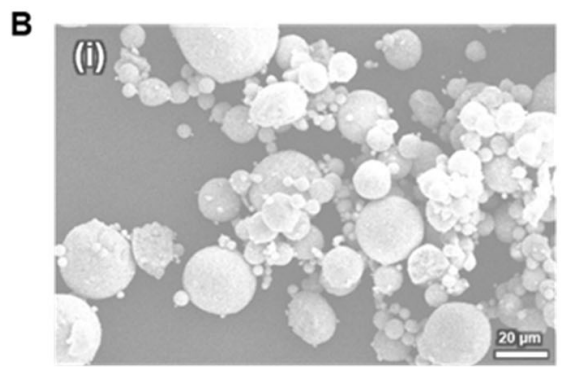

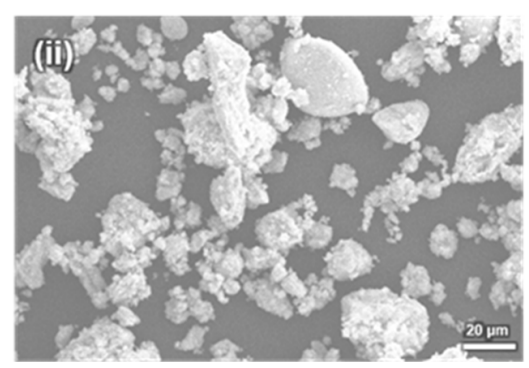

C

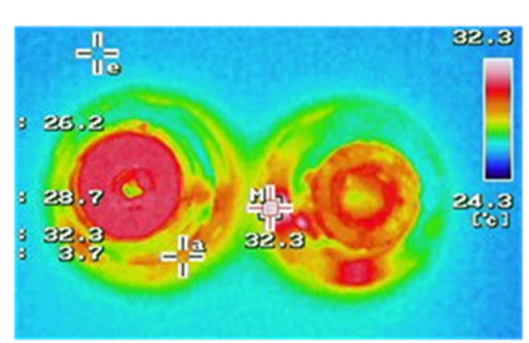

Fig. 5. Mechanistic studies. (A) Radical scavenger experiments. (B) SEM images of $\mathrm{BaTiO}_{3}$ particles (i) before and (ii) after ball milling (30 Hz; $60 \mathrm{~min}$ ); scale bars in the TEM images (bottom right): $20 \mu \mathrm{m}$. (C) Thermographic image of the milling jar after the mechanoredox arylation of $\mathbf{2 a}$ with 1a. See supplementary materials for details.

To demonstrate the robustness of the mechano-redox transformations, we conducted the borylation of $\mathbf{1 k}$ with $\mathrm{BaTiO}_{3}$ in air using a hammer (Fig. S8 and movie S1). First, the reaction mixture was prepared by gentle grinding in a mortar. Subsequently, the mixture was wrapped in a piece of a weighing paper and placed in a zipper-locking plastic bag, followed by striking with a hammer over 200 times. Even under these crude conditions, the mechano-redox borylation product $\mathbf{5 i}$ was obtained in $43 \%$ yield as assessed by NMR integration.

The present mechanoredox reactions can be carried out on gram scale without the use of large amounts of dry and degassed organic solvents in air, and do not require special operating conditions. This operational simplicity suggests that the present approach may complement existing photoredox transformations in a practical and environmentally friendly manner. Beyond the immediate benefits of this protocol, our strategy could be applicable to light-sensitive or lightabsorbing substrates that cannot be subjected to conventional photo-redox systems.

\section{References and notes:}


1. C. Stephenson, T. Yoon, D. W. C. MacMillan, Visible Light Photocatalysis in Organic Chemistry (Wiley-VCH, Weinheim, Germany, ed. 1, 2018).

2. C. K. Pier, D. A. Rankic, D. W. C. MacMillan, Chem. Rev. 113, 5322-5363 (2013).

3. N. A. Romero, D. A. Nicewicz, Chem. Rev. 116, 10075-10166 (2016).

4. C.-S. Wang, P. H. Dixneuf, J.-F. Soulé, Chem. Rev. 118, 7532-7585 (2018).

5. K. L. Skubi, T. R. Blum, T. P. Yoon, Chem. Rev. 116, 10035-10074 (2016).

6. T. Friščić, J. Mater. Chem. 20, 7599-7605 (2010).

7. S.-E. Zhu, F. Li, G.-W. Wang, Chem. Soc. Rev. 42, 7535-7570 (2013).

8. P. Baláž, Mechanochemistry in Nanoscience and Minerals Engineering (Springer, 2008).

9. R. Boulatov, Polymer Mechanochemistry (Switzerland, Springer, 2015).

10. S. L. James, C. J. Adams, C. Bolm, D. Braga, P. Collier, T. Friščić, F. Grepioni, K. D. M. Harris, G. Hyett, W. Jones, A. Krebs, J. Mack, L. Maini, A. G. Orpen, I. P. Parkin, W. C. Shearouse, J. W. Steed, D. C. Waddell, Chem. Soc. Rev. 41, 413-447 (2012).

11. G.-W. Wang, Chem. Soc. Rev. 42, 7668-7700 (2013).

12. J.-L. Do, T. Friščić, ACS Cent. Sci. 3, 13-19 (2017).

13. J. G. Hernández, C. Bolm, J. Org. Chem. 82, 4007-4019 (2017).

14. D. Tan, T. Friščić, Eur. J. Org. Chem. 18-33 (2018).

15. J. L. Howard, Q. Cao, D. L. Browne, Chem. Sci. 9, 3080-3094 (2018).

16. J. Andersen, J. Mack, Green Chem. 20, 1435-1443 (2018).

17. C. Bolm, J. D. Hernández, Angew. Chem., Int. Ed. 58, 3285-3299 (2019).

18. F. Gomollón-Bel, Chem. Int. 41, 12-17 (2019).

19. J. C. Robertson, M. L. Coote, A. C. Bissmber, Nat. Rev. Chem. 3, 290-304 (2019).

20. J. Liang, J. M. Fernández, J. Am. Chem. Soc. 133, 3528-3534 (2011).

21. P. Dopieralski, J. Ribas-Arino, P. Anjukandi, M. Krupicka, J. Kiss, D. Marx, Nature Chem. 5, 685-691 (2013).

22. H. Yan, F. Yang, D. Pan, Y. Lin, J. N. Hohman, D. Solis-Ibarra, F. H. Li, J. E. P. Dahl, R. M. K. Carlson, B. A. Tkachenko, A. A. Fokin, P. R. Schreiner, G. Galli, W. L. Mao, Z.-X. Shen, N. A. Melosh, Nature 554, 505-510 (2018).

23. S. Ikeda, T. Takata, M. Komoda, M. Hara, J. N. Kondo, K. Domen, A. Tanaka, H. Hosono, H. Kawazoe, Phys. Chem. Chem. Phys. 1, 4485-4491 (1999).

24. M. Hara, H. Hasei, M. Yashima, S. Ikeda, T. Takata, J. N. Kondo, K. Domen, Appl. Catal. A-Gen. 190, 35-42 (2000).

25. Z. L. Wang, J. Song, Science 312, 242-246 (2006).

26. X. Wang, J. Song, J. Liu, L. Wang, Science 316, 102-105 (2007). 
27. Y. Qin, X. Wang, Z. L. Wang, Nature 451, 809-813 (2008).

28. K.-S. Hong, H. Xu, H. Konishi, X. Li, J. Phys. Chem. Lett. 1, 997-1002 (2010).

29. H. Mohapatra, M. Kleiman, A. P. Esser-Kahn, Nature Chem. 9, 135-139 (2017).

30. M. B. Starr, J. Shi, X. Wang, Angew. Chem., Int. Ed. 51, 5962-5966 (2012).

31. M. B. Starr, X. Wang, Sci. Rep. 3, 2160 (2013).

32. H. Lin, Z. Wu, Y. Jia, W. Li, R.-K. Zheng, H. Luo, Appl. Phys. Lett. 104, 162907 (2014).

33. W. Lv, L. Kong, S. Lan, J. Feng, Y. Xiong, S. Tian, J. Chem. Technol. Biotechnol. 92, 152-156 (2017).

34. M. B. Starr, X. Wang, Nano Energy 14, 296 (2015).

35. W. Zhenhua, L. Francesca, F. Marco, W. Zongyu, Y. Jianjun, W. Zhanhua, X. Hesheng, K. Matyjaszewski, ACS Macro Lett. 8, 161 (2019).

36. K. Matyjaszewski, Macromolecules 45, 4015 (2012).

37. D. P. Hari, P. Schroll, B. König, J. Am. Chem. Soc. 134, 2958-2961 (2012).

38. J. Yu, L. Zhang, G. Yan, Adv. Synth. Catal. 354, 2625-2628 (2012).

39. C. P. Andrieux, J. Pinson, J. Am. Chem. Soc. 125, 14801-14806 (2003).

40. J. H. Haeni, P. Irvin, W. Chang, R. Uecker, P. Reiche, Y. L. Li, S. Choundhury, W. Tian, M. E. Hawley, B. Craigo, A. K. Tagantsev, X. Q. Pan, S. K. Streiffer, L. Q. Chen, S. W. Kirchoefer, J. Levy, D. G. Schlom, Nature 430, 758-761 (2004).

41. T. Friščić, S. L. Childs, S. A. A. Rizvi, W. Jones, CrystEngComm 11, 418-426 (2009).

42. M. E. Cinar, T. Ozturk, Chem. Rev. 115, 3036 (2015).

43. Y. Segawa, H. Ito, K. Itami, Nat. Rev. Mater. 1, 15002 (2016).

44. Y. Segawa, T. Maekawa, K. Itami, Angew. Chem., Int. Ed. 54, 66-81 (2015).

Pls add the rest of the references (from the supplement) here: the full list will be published online.

45. R. Cai, M. Lu, E. Y. Aguilera, Y. Xi, N. G. Akhmedov, J. L. Petersen, H. Chen, X. Shi, Angew. Chem. Int. Ed. 54, 8772-8776 (2015).

46. T. Taniguchi, M. Imoto, M. Takeda, F. Matsumoto, T. Nakai, M. Mihara, T. Mizuno, A. Nomoto, Ogawa, Tetrahedron 27, 4132-4140 (2016).

47. S. Zhang, Z. Tang, W. Bao, J. Li, B. Guo, S. Huang, Y. Zhang, Y. Rao, Org. Biomol. Chem. 17, 4364-4369 (2019).

48. L. Wang, Z.-X. Wang, Org. Lett. 9, 4335-4338 (2007).

49. W. Su, S. Urgaonkar, P. A. McLaughlin, J. G. Verkade, J. Am. Chem. Soc. 126, 16433- 
16439 (2004).

50. N. Morimoto, K. Morioku, H. Suzuki, Y. Nakai, Y. Nishina, Chem. Commun. 53, 72267229 (2017).

51. E. Yamamoto, K. Izumi, Y. Horita, H. Ito, J. Am. Chem. Soc. 134, 19997-20000 (2012).

52. B. Wrackmeyer, Prog. Nucl. Magn. Reson. Spectrosc. 12, 227-259 (1979).

53. N. F. Pelz, A. R. Woodward, H. E. Burks, J. D. Sieber, J. P. Morken, J. Am. Chem. Soc. 126, 16328-16329 (2004).

54. C. Kleeberg, L. Dang, Z. Lin, T. B. Marder, Angew. Chem. Int. Ed. 48, 5350-5354 (2009).

55. W. K. Chow, O. Y. Yuen, C. M. So, W. T. Wong, F. Y. Kwong, J. Org. Chem. 77, 35433548 (2012).

56. F. Mo, Y. Jiang, D. Qiu, Y. Zhang, J. Wang, Angew. Chem. Int. Ed. 49, 1846-1849 (2010).

57. T. Yamamoto, T. Morita, J. Takagi, T. Yamakawa, Org. Lett. 13, 5766-5769 (2011).

58. M. Beinhoff, W. Weigel, M. Jurczok, W. Rettig, C. Modrakowski, I. Brüdgam, H. Hartl, A. D. Schlüter, Eur. J. Org. Chem. 3819 (2001).

Acknowledgments: Funding: This work was supported by the Japan Society for the Promotion of Science (JSPS) through KAKENHI grants 18H03907, 17H06370, 19K15547, and by the JST CREST grant number JPMJCR19R1 as well as by the Institute for Chemical Reaction Design and Discovery (ICReDD), which was established by the World Premier International Research Initiative (WPI), MEXT, Japan. Y. P. thanks the Otsuka Toshimi Scholarship Foundation for a scholarship. We thank D. F. Toste and T. Shimada for advices on the preparation of this manuscript. Author contributions: H.I. came up with the original idea; K.K. and H.I. directed the project; K.K. and H.I. designed the experiments; K.K. and Y.P. performed the experiments; A.M. prepared ceramic materials used in this study; K.K. and H.I. wrote the manuscript with feedback from the other authors. Competing interests: The authors declare no competing interests; Data and materials availability: All data are available in the supplementary materials.

\section{Supplementary Materials:}

Materials and Methods

Figures $\mathrm{S} 1$ to $\mathrm{S} 9$

Tables S1 to S5

Movie S1

References (43-56)

NMR Spectra 